\title{
THE NEED FOR A DYNAMICAL CLIMATE REANALYSIS
}

\author{
by Lennart Bengtsson, Phil Arkin, Paul Berrisford, Philippe Bougeault, Chris K. Folland, \\ Chris Gordon, Keith Haines, Kevin I. Hodges, Phil Jones, Per Kallberg, Nick Rayner, \\ Adrian J. Simmons, Detlef Stammer, Peter W. Thorne, Sakari Uppala, and Russell S. Vose
}

Resolution of a number of key climate research issues likely depends on how well the community benefits most from a dedicated dynamical reanalysis.

T he Earth's climate is dominated by diverse and changeable natural processes over a wide range of time and space scales (e.g., Folland et al. 2001). This includes changes related to transient synoptic weather systems and to phenomena on much longer time scales, such as the quasibiennial oscillation (QBO) and El Niño-Southern Oscillation (ENSO) with time scales up to several years. Especially intriguing are the climate variations related to the North Atlantic Oscillation (NAO). The difference between a mild and cold winter in northwest Europe, for example, is mainly caused by noticeable storm-track variations that are not yet fully understood.

AfFiliations: BengtsSon, Haines, AND HODges-Environmental System Science Centre, University of Reading, Reading, United Kingdom; ARKIN-Earth System Science Interdisciplinary Center, University of Maryland, College Park, College Park, Maryland; BERRISFORD-NCAS Centre for Global Atmospheric Modelling, University of Reading, Reading, United Kingdom; BOUgEAULT, Kallberg, Simmons, and Uppala-European Centre for MediumRange Weather Forecasts, Reading, United Kingdom; FolLAND, Gordon, Rayner, And Thorne-Hadley Centre, Met Office, Exeter, United Kingdom; JonEs-Climate Research Unit, University of East Anglia, Norwich, United Kingdom; StAMmER-Institut fuer Meereskunde, Zentrum fuer Meeres- und Klimaforschung,
Some of the climate variations are driven by internal phenomena in the atmosphere, others are related to interactions between the atmosphere and the oceans and between the atmosphere and the land surfaces, and still others are due to solar and volcanic influences. At the same time, Earth's climate is increasingly exposed to anthropogenic changes, such as increasing greenhouse gases.

Because of the high variability over a broad range of time scales, the climate of the Earth cannot be properly described by time averages only, but instead requires continuous monitoring on a daily resolution or higher because many atmospheric features undergo rapid changes. Such high-resolution

University of Hamburg, Hamburg, Germany; VosE-Climate Analysis Branch, National Climate Data Centre, Asheville, South Carolina

CORRESPONDING AUTHOR: Professor Lennart Bengtsson, Environmental System Science Centre, University of Reading, Harry Pitt Building, Whiteknights P.O. Box 238, Reading RG6 6AL, United Kingdom

E-mail: bengtsson@dkrz.de

DOI:10.1I75/BAMS-88-4-495

In final form I November 2006

@2007 American Meteorological Society 
datasets are required for understanding the climate, and in particular for providing reliable datasets for the validation and development of models for the atmosphere, oceans, and land surfaces. At the same time, there is a need for continuous records of the longest possible duration, because certain studies require data over a century or longer. Such data would help to clarify the large climate variations in the twentieth century, with the warm period in the 1930s and 1940s followed by a cooler period in the 1960s and 1970s, and multidecadal variations in the behavior of the El Niño-Southern Oscillation phenomenon.

Unfortunately, climate research cannot be effectively done from in situ observations alone, because these are too sparse and irregularly distributed. Recent space-based observations have much better coverage but suffer from other limitations, notably temporal and spatial inhomogeneity, restricting their general use for assessing climate (Mason et al. 2003). For some purposes a promising approach has been to make use of daily analysis of the state of the atmosphere as carried out routinely by the meteorological services. Such data have been used in climate research, particularly to study mechanisms, but have suffered from the many changes that have taken place in operational numerical weather prediction (NWP), thereby introducing many inhomogeneities and considerably limiting their value for assessing climate changes. A step forward was taken with the suggestion made by Bengtsson and Shukla (1988) and Trenberth and Olson (1988) that atmospheric observations should be reanalyzed over a period of time long enough to be useful for climate studies by using a fixed dynamical system to assimilate the observations. Such reanalyses were initiated in the mid-1990s (Kalnay et al. 1996; Gibson et al. 1997; Kistler et al. 2001) and have contributed significantly to a more detailed and comprehensive understanding of the dynamics of the Earth's atmosphere (Hoskins and Hodges 2002; Hodges et al. 2003). Recent such reanalyses include the National Centers for Environmental Prediction-National Center for Atmospheric Research (NCEP-NCAR) reanalyses covering the period from 1948 until present, the 40-yr European Centre for Medium-Range Weather Forecasts (ECMWF) Re-Analyses (ERA-40) from 1957 to 2002 (Uppala et al. 2005), and the Japanese Reanalysis (JRA-25) from 1979 to 2004.

Reanalyses have been used for a number of studies, in particular for atmospheric model validation. The reanalyses have contributed to clarification of the relative importance of model and data assimilation improvements versus observational improvements for NWP over the last decades. This has shown that observational improvements are the main cause for better forecasts in the Southern Hemisphere, while for the Northern Hemisphere more accurate modeling and data assimilation dominate. The climate community has started to explore the reanalyses for different applications and note the great potential value of having global homogeneous datasets covering the troposphere and the stratosphere for long periods.

However, it appears that the reanalyses suffer from a number of limitations that unfortunately restrict their general use, especially for climate applications. One such restriction is due to considerable changes in the observing system, which has evolved significantly over the last 50-100 years from surface observations before the 1940s to the present largely space-based system. This creates difficulties in reconstructing longerterm climate trends (Bengtsson et al. 2004a; Simmons et al. 2004), especially for periods that stretch back beyond the major upgrade of the observing system in the late 1970s when comprehensive satellite coverage was established.

To improve the estimation of long-term climate trends it is also required that the state of the surface is known, in particular the sea surface temperature (SST) and sea ice distribution. Major efforts are needed to bring together more of the available data into a coherent form that is suitable for climate reanalysis. Significant progress is being made (Diaz et al. 2002).

Another difficulty relates to the assessment of energy and water fluxes, particularly between the atmosphere and the surface of the Earth. Such fluxes cannot be directly obtained from present observations, but must be calculated within a model framework suitably constrained by observations. Present reanalyses have difficulty in handling this and fail to ensure a longer-term global balance of fluxes. As a consequence, the evaporation-precipitation $(E-P)$ over oceans is not necessarily balanced by the precipitation-evaporation $(P-E)$ over land, as should be the case, because there is no built-in integral constraint in the assimilation.

Our discussions at a reanalysis workshop at the University of Reading, United Kingdom highlighted a number of central issues in climate research. ${ }^{1}$ We describe here how these research needs may benefit from a dedicated reanalysis; these include a more in-depth understanding of the general circulation

\footnotetext{
${ }^{1}$ The workshop took place at the university's Environmental System Science Center, 22-23 January 2005.
} 
of the atmosphere, and a more reliable assessment of climate trends, the hydrological cycle, and the calculation of energy fluxes over the oceans.

\section{UNDERSTANDING THE ATMOSPHERIC} CIRCULATION. Progress in gaining a better understanding of the atmospheric circulation will result from studies in many areas. For the troposphere these studies might include the analysis of storm tracks and blocking, the hydrological cycle, the Madden-Julian oscillation (MJO), and ENSO, while for the stratosphere these studies might include the Brewer-Dobson circulation and the QBO. All of these studies and more would benefit from high-quality reanalysis data.

At the most fundamental level the Earth's atmosphere and oceans act to transport heat from the Tropics, where there is a net input, to the polar regions, where there is a net loss. Therefore, a better depiction of heating and heat transport is key to gaining a better insight into the atmospheric and oceanic circulations. The heating depends on many effects, such as solar and terrestrial net radiation, land/ocean surface processes, and the hydrological cycle. In forecast models these processes are often represented by parameterizations that are inherently subject to error. The result is a net heating field that is inconsistent with the flow, and a flow that is inconsistent with the heating. Because of the complexity of the mutually interacting processes that result in the net heating field, it is difficult to ascribe causes to these inconsistencies, but any improvement in the heating field would be mirrored by an improvement in the flow.

One component of the heating field is due to the transient eddies within storm tracks that transport heat and moisture to higher latitudes. Thus, a better depiction of the storm tracks and blocking (where the transient eddies are blocked from their usual path in the storm track) would lead to a more faithful representation of the atmospheric circulation. For example, current work suggests that ERA-40 data give a deficient representation of Southern Hemisphere blocking in the presatellite years. Blocking frequencies appear to be much reduced in this period compared to the later years. While it is possible that this represents real variability in the climate system, it is quite likely that the reanalyses fail to capture the true extent of Southern Hemisphere blocking in the presatellite years, which is linked with the representation of the storm tracks and their transport of heat and moisture.

Diagnosis of the atmospheric circulation, which leads to a better understanding thereof, can often entail large amounts of computing effort and is often unnecessarily duplicated by individual research groups. It would be useful if a more substantial part of this work could be done jointly as part of a future reanalysis project. It might, for example, be useful to produce a more comprehensive set of diagnostics in addition to the usual reanalysis products.

\section{ASSESSMENT OF CLIMATE TRENDS.}

Climate datasets of tropospheric temperature from satellites, radiosondes, and reanalyses have highlighted uncertainty regarding the true multidecadal temperature trends aloft. Trend calculations from upper-air data generally exhibit less warming than surface data do. Using satellite-derived Microwave Sounding Unit (MSU) brightness temperature three different publications yield trends from +0.03 to +0.17 $\mathrm{K} \mathrm{decade}^{-1}$, and all with estimated error bars so small that there is no significant overlap between them (Thorne et al. 2005). The differences are structural and relate to the way in which suspected nonclimatic biases in the observations have been identified and homogenized. These error estimates are, therefore, meaningless because they fail to account for the true uncertainty. Similar problems occur with radiosondes, where changes in the radiosonde network, the introduction of new types of sondes, and the use of different empirical correction procedures for systematic measurement errors have lead to similar problems as for MSU data. The surface network is more robust, but suffers from incomplete and spatially biased coverage as well as exposure to urbanization effects.

Recalculating trends from a climate quality reanalysis could address several of the difficulties, particularly so if observing system experiments were to be performed, because observations from specific observing systems are systematically compared with model information, as well as observations from other observing systems. However, this requires the use of data from a network of radiosonde, surface-based, and satellite-based observations that are specifically prevalidated with respect to systematic biases. Long-term trends aloft in the current generation of reanalyses imply that the models themselves cannot absolutely correct the bias in grossly inhomogeneous input data. Possible ways to overcome this have been suggested by Dee and Todling (2000). Included therein is an estimation of bias correction in real time during the assimilation, making it possible to adapt to slow changes in bias-related instrumental drifts, etc. Such an approach is also a practical necessity in view of the large number of data from different satellite instruments mostly requiring specific bias 
correction. A bias correction along these lines will be implemented as an integrated part of a future reanalysis system at ECMWF (D. P. Dee 2006, personal communication).

THE WATER CYCLE. The dynamical circulation of the atmosphere largely determines the water cycle. Precipitation is coupled with the convergence of water vapor, water vapor is transported by the winds, and evaporation takes place where there is a negative vertical gradient of water vapor above the surface. One of the difficulties in reproducing the water cycle with a model is that the model cannot resolve small-scale features, such as convective systems, which in many parts of the world produce a large part of the total precipitation. Convective systems have to be parameterized and as such become strongly model dependent. However, precipitation from convective systems is in turn mainly determined by the large-scale convergence of water vapor, and there is difficulty in modeling the amount that evaporates from the ground and then feeds into the convective systems. This is an inherent problem that is likely to gradually improve with better models. Another problem is related to the data assimilation. We describe this problem with an example from ERA-40. Andersson et al. (2005) explain how the analyses were moistened over tropical oceans by the assimilation of satellite data. The infrared Vertical Temperature Profile Radiometer (VTPR) and High Resolution Infrared Radiation Sounder (HIRS) data were assimilated only in regions judged to be cloud free, and Special Sensor Microwave Imager (SSM/I) data were assimilated only in regions judged to be rain free. Background forecasts in these regions were drier than that indicated by the data, resulting in positive humidity increments. The problem occurred because the humidity changes were spread over areas that were too wide, adding moisture in areas where the atmosphere was already close to saturation as well as in neighboring areas indicated as being too dry by the observations. This generated a positive feedback in successive analysis steps that created too much precipitation over tropical ocean areas.

This problem illustrates the complexity of the data assimilation process. Difficulties such as this one limit the usefulness of reanalyses for the study of the hydrological cycle (Hagemann et al. 2005). We believe major efforts are required to overcome this, including the use of precipitation measurements from satellite and in situ data. Hou et al. (2001) have shown positive impacts from the use of Tropical Rainfall Measuring
Mission (TRMM) data. Other difficulties with the hydrological cycle in data assimilation are related to the handling of the diurnal precipitation cycle and land surface processes.

\section{REANALYSIS FLUXES OVER THE OCEANS.}

The poor quality of surface fluxes of heat and freshwater over the oceans is a major problem with current reanalysis systems such as ERA-40. An accurate assessment of these fluxes is precisely the type of a climatically important diagnostic that one would like to obtain from reanalysis. Much of the problem may lie with atmospheric model parameterizations of clouds and precipitation, which need to be improved; but benefits may also follow from adding constraints to the assimilation procedure. The short period of the current atmospheric assimilation windows (6-12 h) and the lack of any thermodynamic ocean representation (i.e., the use of fixed SSTs) allow surface heat fluxes to have large mean biases. Similarly, the lack of any freshwater constraints means that the $E-P$ is not forced to balance in any spatially or temporally averaged sense. The following number of possibilities exist to mitigate these problems:

1) There is evidence that smaller spatial scales in the SST boundary lead to much stronger atmospheric turbulence, leading to biases in air-sea heat and evaporative fluxes. Future reanalyses could be carried out with higher-resolution SST data, but probably only back to the early 1980s. Close attention to the quality and continuity, particularly of the SST and sea ice data, during future reanalyses would likely give significant flux improvements.

2) Reanalysis flux products (e.g., precipitation and evaporation) require the model to be run for some time period $(6,12,24 \mathrm{~h})$, allowing some flexibility in defining products. There is the capability for involving a greater comparison of different flux products with external estimates from buoys, etc., and engaging external experts from the oceanographic community in these choices. It is already known that $E$ - $P$ fields become balanced much more rapidly in the current operational ECMWF model compared with the ERA-40 products, suggesting that there is considerable possibility for improvements in reanalysis fluxes in the future. A possible way to reduce the spinup/spin-down problem is the incremental analysis update (IAU) approach of Bloom et al. (1996). IAU incorporates analysis increments into a model integration in a gradual manner, using 
the analysis increments as constant forcing. This is introduced into the prognostic equations of the model over a 6 -h period centered on the analysis time. In that respect it acts as a low-pass filter on the assimilating system's response to analysis increments.

3) It is common practice in the climate modeling community to require the mean top-ofatmosphere (TOA) flux in the Atmospheric Model Intercomparison Project (AMIP)-type simulations to be less than $\sim 1 \mathrm{~W} \mathrm{~m}^{-2}$. This is essentially an observational constraint on the system and is achieved by the appropriate tuning of the physical parameterizations. If the TOA flux is significantly out of balance in AMIPtype runs, the surface flux budget clearly will not balance globally. ERA-40 apparently has a fairly constant $7 \mathrm{~W} \mathrm{~m}^{-2}$ imbalance. Consideration should be given to appropriate tuning to reduce the mean TOA flux to within the bounds set by the observed radiation budget.

4) Use of four-dimensional variational data assimilation (4DVAR) over a longer time window, along with some kind of slab ocean, would restrict errors in surface heat fluxes. For example, a surface heat flux bias of $20 \mathrm{~W} \mathrm{~m}^{-2}$ (a typical ECMWF flux bias) applied to a typical ocean mixed layer (tropical or seasonal) of 20-m depth for a period of 1 month (possible extended 4DVAR period) would lead to a temperature drift of $0.6^{\circ} \mathrm{C}$. Constraints on fitting the observational SST may then be sufficient to reduce such a surface flux error, assuming the right atmospheric control variable can be identified.

5) Taking this idea further, there is great scope for developing the whole area of the coupled model data assimilation over the next few years. Current seasonal forecast models often exhibit large initialization SST shocks, and a full coupled assimilation system should reduce these shocks, as well as give better conditioned air-sea flux estimates for climate reanalysis purposes. Reanalysis with a full coupled model would allow imbalances in air-sea fluxes to be constrained against atmospheric budgets, for example, as influenced by clouds, together with parameters affecting ocean transports. Balancing budgets on a range of time scales, even up to a year or more, would be a useful constraint, and much further investigation in this area is needed. The advent of Argo subsurface ocean temperature and salinity data with worldwide coverage could help such an activity considerably.
Perhaps the most useful approach over the coming years is to try to engage a wider community of experts to help tune the data assimilation and reanalysis methods to get more optimal products for climate studies. Reanalyses are only feasible in the context of the infrastructure of the operational forecasting centers, but by engaging the wider oceanography and climate modeling communities in collaboration, and giving them a role in shaping future reanalysis products, there is an excellent opportunity to improve our understanding of longer-term climate variability over the past century.

\section{DEVELOPING REANALYSIS FOR CLIMATE \\ RESEARCH. There was a consensus at the Reading} workshop that reanalyses are a most important contribution to climate research, reiterating similar views expressed at a climate workshop in Boulder, Colorado, in 2003 (Arkin 2003). We welcomed the plans from the operational agencies to undertake future reanalyses with improved models and data assimilation. It appears that several of the problems found in the present reanalyses will diminish with the implementation of more advanced methods to handle physical processes in the models as well as further improvements in the data assimilation. These will include the following:

1) Model and observational biases will be identified. Such biases preferably need to be defined prior to a reanalysis. Of particular importance are biases changing in time. This is not uncommon for upper-air data.

2) Further reductions in systematic model errors are needed, including the handling of land surface processes and the parameterization of processes of importance for the hydrological cycle.

3) Further improvements in the horizontal resolution of the model to the order of some $50 \mathrm{~km}$ (T250 or similar), as well as the employment of a vertical resolution high enough to be able to handle QBO and other important stratosphere processes satisfactorily are needed (Giorgetta et al. 2002).

4) Implementation of full four-dimensional data assimilation systems similar to those increasingly used in operational NWP is needed in order to handle nonsynoptic and irregularly distributed observations more consistently. Other promising methods are ensemble data assimilation (Whitaker et al. 2004; Compo et al. 2006).

Such model and assimilation changes are likely to address some of the needs for climate research 
discussed above, including a better handling of improved flux calculations between the atmosphere and the surface. However, the experiences so far point to the need for a more active involvement by the climate community in the development of future reanalyses. This will include the following:

1) the provision of the best possible fields of SST and sea ice concentration, including the assessed uncertainties. [This will be of highest priority for a reanalysis addressing studies prior to the 1950s (N. A. Rayner et al. 2006). Incorrect or incomplete data can be misleading in estimating climate change. Similarly, better datasets for land surface conditions including snow cover are required.];

2) recovery of synoptic surface meteorological data and radiosonde upper-air data to fill gaps in the observational records held by reanalysis centres (This is particularly important for the presatellite years.);

3) much more accurately bias-corrected radiosonde and satellite temperature data for the free atmosphere with assessed uncertainties that importantly include, and remove as far as possible, the structural uncertainties;

4) experimental reanalyses using selected sets of observations (Bengtsson et al. 2004b) to explicitly assess the impact of different observations and provide quantitative justification for assimilation decisions and a focus for data rescue and homogenization efforts (Such experimental studies can now be undertaken by remote research groups with high-speed access to advanced data assimilation systems and databases made available by operational agencies such as ECMWF. An example, here, might be to omit satellite data for the period since 1979. Another might use the original and the bias-corrected sondes to see the impact of different adjustment procedures.); and

5) experiments with the use of coupled models in data assimilation drawing on the experiences in the oceanographic community.

The production of reanalyses is a major undertaking that requires both broad technical experience in addition to a scientific understanding. A long-term commitment preferably by an agency with an operational mission in NWP or a dedicated effort by research agencies (such as the Global Modeling and Assimilation Office at the National Aeronautics and Space Administration) is conse- quently required. We strongly support an enhancement of the partnership between the producers of reanalyses and the climate community, with particular emphasis toward improving the next generation of reanalyses.

\section{REFERENCES}

Andersson, E., and Coauthors, 2005: Assimilation and modeling of the atmospheric hydrological cycle in the ECMWF forecasting system. Bull. Amer. Meteor. Soc., 86, 387-402.

Arkin, P., 2003: Ongoing analysis of the climate system: A workshop report. $48 \mathrm{pp}$. [Available online at www. joss.ucar.edu/joss_psg/meetings/Archived/climatesystem/index.html.]

Bengtsson, L., and J. Shukla, 1988: Integration of space and in situ observations to study global climate change. Bull. Amer. Meteor. Soc., 69, 1130-1143.

_-, K. Hodges, and S. Hagemann, 2004a: Can climate trends be calculated from reanalysis data? J. Geophys. Res., 109, D11111, doi:10.1029/2004JD004536.

— — , and — 2004b: Sensitivity of the ERA40 Re-Analyses to the observing system: Determination of the global atmospheric circulation from reduced observations. Tellus, 56A, 456-471.

Bloom, S. C., L. L. Takacs, A. M. da Silva, and D. Ledvina, 1996: Data assimilation using incremental analysis updates. Mon. Wea. Rev., 124, 1256-1271.

Compo, G. P., J. S. Whitaker, and P. D. Sardeshmukh, 2006: Feasibility of a 100-year reanalysis using only surface pressure data. Bull. Amer. Meteor. Soc., 87, 175-190.

Dee, D. P., and R. Todling, 2000: Data assimilation in the presence of forecast bias: The GEOS moisture analysis. Mon. Wea. Rev., 128, 3268-3282.

Diaz, H. F., C. K. Folland, T. Manabe, D. E. Parker, R. W. Reynolds, and S. D. Woodruff, 2002: Workshop on advances in the use of historical marine climate data (Boulder, Co., USA, 29th Jan-1st Feb 2002). WMO Bulletin, Vol. 51, 377-380.

Folland, C. K., and Coauthors, 2001: Observed climate variability and change. Climate Change 2001: The Scientific Basis, J. T. Houghton et al., Eds., Cambridge University Press, 99-181.

Gibson, J. K., P. Kållberg, S. Uppala, A. Nomura, A. Hernandez, and E. Serrano, 1997: ERA description: ECMWF ERA-15 Project Report Series No. 1, $71 \mathrm{pp}$.

Giorgetta, M. A., E. Manzini, and E. Roeckner, 2002: Forcing of the quasi-biennial oscillation from a broad spectrum of atmospheric waves. Geophys. Res. Lett., 29, 1245, doi:10.1029/2002GL014756. 
Hagemann, S., K. Arpe, and L. Bengtsson, 2005: Validation of the hydrological cycle in ERA40. Rep. on Earth System Science Volume 10, MPI for Meteorology, Hamburg, Germany, 42 pp.

Hodges, K. I., B. J. Hoskins, J. Boyle, and C. Thorncroft, 2003: A comparison of recent reanalysis datasets using objective feature tracking: Storm tracks and tropical easterly waves. Mon. Wea. Rev., 131, 2012-2037.

Hoskins, B. J., and K. I. Hodges, 2002: New perspectives on the Northern Hemisphere winter storm tracks. J. Atmos. Sci., 59, 1041-1061.

Hou, A. Y., S. Q. Zhang, A. M. da Silva, W. S. Olson, C. D. Kummerow, and J. Simpson, 2001: Improving global analysis and short-range forecast using rainfall and moisture observations derived from TRMM and SSM/I passive microwave sensors. Bull. Amer. Meteor. Soc., 82, 659-679.

Kalnay, E., and Coauthors, 1996: The NCEP/NCAR 40-Year Reanalysis Project. Bull. Amer. Meteor. Soc., 77, 437-471.

Kistler, R., and Coauthors, 2001: The NCEP-NCAR 50-year reanalysis: Monthly means CD-ROM and documentation. Bull. Amer. Meteor. Soc., 82, 247-267.

Mason, P. J., M. Manton, D. E. Harrison, A. Belward, A. R. Thomas, and D. K. Dawson, Eds., 2003: The second report on the adequacy of the global observing systems for climate in support of the UNFCCC. GCOS Rep. 82, WMO TD/1143, 85 pp.

Rayner, N., P. Brohan, D. E. Parker, C. K. Folland, J. Kennedy, M. Vanicek, T. Ansell, and S. F. B. Tett, 2006: Improved analyses of changes and uncertainties in sea surface temperature measured in situ since the mid-nineteenth century: The HadSST2 dataset. J. Climate, 19, 446-469, doi:10.1175/JCLI3637.1.

Simmons, A. J., and Coauthors, 2004: Comparison of trends and low-frequency variability in CRU, ERA-40 and NCEP/NCAR analyses of surface air temperature. J. Geophys. Res., 109, D24115, doi:10.1029/2004JD005306.

Thorne, P. W., D. E. Parker, J. R. Christy, and C. A. Mears, 2005: Uncertainties in climate trends: Lessons from upper-air temperature records. Bull. Amer. Meteor. Soc., 86, 1437-1442.

Trenberth, K. E., and J. G. Olson, 1988: An evaluation and intercomparison of global analyses from NMC and ECMWF. Bull. Amer. Meteor. Soc., 69, 1047-1057.

Uppala, S. M., and Coauthors, 2005: The ERA-40 reanalysis. Quart. J. Roy. Meteor. Soc., 131, 2961-3012.

Whitaker, J. S., G. P. Compo, X. Wei, and T. M. Hamill, 2004: Reanalysis without radiosondes using ensemble data assimilation. Mon. Wea. Rev., 132, 1190-1200. 